\title{
ELEMENTOS DE MARKETING AMBIENTAL PARA O PINHEIRO-DO-PARANÁ BASEADOS NA PERCEPÇÃO DE SEU VALOR PELA COMUNIDADE RURAL PARANAENSE
}

\author{
Environmental Marketing Components to Parana Pine based on \\ Perception Value by the Rural Community in Parana State
}

\begin{abstract}
Arnaldo Carlos Muller
Eng. Florestal, Dr., Professor Adjunto da Pontifícia Universidade Católica do Paraná e Coordenador Geral do Instituto do Desenvolvimento Sustentável, Curitiba - PR. e-mail: arnaldo.muller@pucpr.br

Roberto Baptista Nadal

Eng. Florestal, Especialista em Gestão Empresarial, ISAE-FGV, Setor Celulose e Papel, Curitiba - PR. e-mail: rbnadal@jari.com.br
\end{abstract}

Leonardo Viana

Turismólogo, Especialização em Ecoturismo. e-mail: leo@viajenavida.com

João Carlos Garzel Leodoro da Silva

Eng. Florestal, Dr., Professor Associado - Departamento de Economia e Extensão Rural -

Universidade Federal do Paraná, Curitiba - PR. e-mail: garzel@ufpr.br

\section{Resumo}

O Pinheiro-do-Paraná é uma espécie florestal que teve grande importância na economia do Sul do Brasil, com maior destaque no Estado do Paraná. Avanços agrícolas e exploração madeireira resultaram no esgotamento de seu potencial econômico. Constatou-se que medidas legais destinadas à sua proteção produziram efeitos inesperados, já que a comunidade rural reduziu o plantio dessa espécie e até vem destruindo as mudas recém-germinadas, temendo perder áreas produtivas com uma espécie acreditada como sem valor de mercado. O Projeto Grimpa, do Instituto do Desenvolvimento Sustentável, procedeu a um levantamento de percepção de importância da Araucária junto à comunidade rural paraense, por meio de uma amostragem com 236 entrevistas. O presente trabalho analisou os dados obtidos, o questionário, método de pesquisa empregado e recomendou medidas de marketing ambiental a serem adotadas pelo Plano Grimpa. A comunidade rural paranaense considera desinteressante o plantio de pinheiro pelas restrições impostas à sua utilização econômica. Verificou-se a restrita existência de plantios de novos pinheirais. Detectou-se a confusão entre os entrevistados sobre a diferença entre araucária e pínus. A população desconhece a legislação vigente sobre a exploração e utilização dessa espécie.

Palavras-chave: Pinheiro-do-Paraná; Araucária; Grimpa; Percepção Ambiental. 


\begin{abstract}
The Parana Pine is a forest species that had great importance in the Southern Brazilian economy, with higher prominence in Parana State. Agricultural advances and lumber exploration had resulted in the strong reduction of its economic potential. It was observed that legal acts concerning its protection caused unexpected effect, once the agricultural community reduced to plant this species and also is destroying the natural regeneration just-germinated, fearing to lose productive areas with a species without market value, wrongly interpreted by them. The Grimpa Project, from the Institute of the Sustainable Development, conducted a perception survey about the Parana-pine species importance for the state agricultural community, taking a sampling of 236 interviews. In this paper it was analyzed the informed data, the efficiency of the applied forms, the used research method and concluded with recommended measures of environmental marketing to be utilized by the Grimpa Plan. The state agricultural community considered uninteresting the araucaria plantation because of the legal imposed restrictions to its economic use. It was verified a restricted existence of new araucaria plantations. It was detected confusion among the interviewed persons about the difference between araucaria and pinus. The rural population is often unaware of the current law applied to the exploration and use of this species.
\end{abstract}

Keywords: Parana-pine; Araucaria; Grimpa; Perception survey.

\title{
INTRODUÇÃO
}

O Pinheiro é um fóssil vivo, de um dos gêneros mais antigos da flora do planeta. Seus primeiros registros são do Período Jurássico, entre 190 e 150 milhões de anos. Perpetuou-se, mas agora, como argumentou IDS (2004), por conta da ação humana, está desaparecendo. Desde a década de 50, no auge da exploração dos pinheirais paranaenses, vozes eminentes se levantaram para alertar sobre os perigos da velocidade daqueles abates florestais à própria economia.

A realidade da área das florestas remanescentes desse ecossistema primitivo é atualmente matéria polêmica: pesquisadores da Universidade Federal do Paraná (2004) mediram-na em 2,7 milhões de hectares, o que significa aproximadamente $24 \%$ de cobertura florestal do bioma ainda existente, dos quais quase $13 \%$ de florestas estão em bom grau de conservação. Por outro lado, dados divulgados por instituições ambientalistas informam haver somente $0,7 \%$ de áreas primitivas ou, como citado: "matas virgens", destacando que estão situadas em terras particulares, muitas pertencentes a indústrias madeireiras (SOS ARAUCÁRIA, 2004). Por conta dos dados das instituições ambientalistas, a espécie consta, desde 1992, na lista de espécies ameaçadas de extinção editada pelo IBAMA (1992) e recentemente entrou em proibição de seu aproveitamento.

Certamente não tem sido evidente o interesse oficial na preservação desta espécie, por exemplo, pelas Unidades de Conservação. Isso se nota no fato de que no Paraná não há nenhuma UC dedicada ao bioma. Em nível nacional, um exemplo crítico está no Parque Nacional de São Joaquim, até hoje não completamente implementado. Com 49.300 hectares, seu ato de criação, em 1961, definiu como objetivo a preservação do ecossistema da Floresta Ombrófila Mista, mas seu primeiro diretor só foi designado 30 anos depois, em cujo tempo ocorreu a dizimação quase completa das suas araucárias.

Os citados remanescentes do Pinheiro-do-Paraná encontram-se em áreas rurais de menor possibilidade de mecanização agrícola, onde ocorre a economia de subsistência, com a exploração de ervamate e pastoreio sob cobertura florestal. Nestas, é freqüente a coleta dos pinhões, de março a agosto, que proporcionam alimento e renda àquelas famílias, justamente numa época em que não há outros cultivos. Tem-se, assim, esta colheita como uma atividade socioeconômica regional relevante, cuja economia vem sendo levantada pela ONG ECOPLAN pelo projeto "Perfil do Socioecossistema de Produção de Pinhão no Paraná", parte do Projeto Pinhão, com apoio e sede no Curso de Engenharia Florestal da UFPR. 
Na linha dos esforços de preservação da espécie, outra questão complexa é a legislação concernente ao Pinheiro do Paraná, Federal e Estadual, com medidas protetoras de várias ordens, culminando na declaração da sua moratória - proibição do aproveitamento econômico - em povoamentos naturais. Análises realizadas sobre os vários diplomas legais mostraram que estão vigentes várias leis, decretos e portarias - alguns com sombreamentos conflitantes, onde as decisões restritivas são entendidas e inferidas. Não é objeto deste documento discutir aqueles diplomas legais, porém este é mais um dos fatores que geram insegurança e aversão dos agricultores à espécie.

Neste meio, surge o Plano Grimpa, proposto pelo IDS - Instituto do Desenvolvimento Sustentável -, uma ONG sediada no Paraná, dedicado a alertar e programar - tangenciando a questão da moratória da espécie - o plantio de 10 milhões de novos pinheiros no Sul do Brasil, inclusive com interesses econômicos.

De acordo com o Plano, "importa que os pinhões sejam plantados em muitas propriedades e em lugares públicos, em áreas de preservação permanente: matas ciliares, morros, reservas legais, nas divisas de terrenos e compondo a paisagem da beira de caminhos. Também, formando matas energéticas, poupança ecológica e para exploração econômica, bem como povoamentos porta-semente." E continua: "Sem que surjam novos pinheirais, pouco adianta restringir o corte das árvores adultas: temos que plantálos, muitos e logo, para salvar a raça. A nossa e as gerações futuras, então, usufruirão os generosos benefícios desta espécie dos frios planaltos do Sul.” (IDS, 2004).

Dentre os seis programas principais apresentados pelo Grimpa, o primeiro foi justamente a realização de uma "Pesquisa sobre a importância do Pinheiro: Consulta à opinião pública sobre a percepção da importância social, ecológica e econômica do Pinheiro e das causas das resistências ao seu plantio, colhendo sugestões sobre como salvar a espécie", cujos procedimentos e resultados são ora considerados.

O objetivo deste trabalho, referenciado em outubro de 2004, é analisar os dados obtidos na pesquisa acima referida. As análises incluíram a formatação do questionário e o método de pesquisa empregado, com vistas a recomendar medidas de marketing ambiental a serem adotadas pelo Plano Grimpa, em favor da Araucaria angustifolia, bem como as destinadas a sanear as deficiências do levantamento realizado, em possíveis replicações.

\section{REVISÃO}

Os estudos antecedentes, utilizando-se de metodologias análogas às empregadas neste, foram realizados por diversos pesquisadores para outros fins, não sendo a presente pesquisa replicação de qualquer outro estudo similar. Assim, cabe revisar os registros sobre a metodologia da pesquisa, enfocando o uso de questionários para entrevistas dirigidas, bem como as questões de percepção ambiental e de valor, notadamente sobre marketing ambiental, as bases da estatística teórica aplicável.

A percepção ambiental está integralmente fundamentada no entendimento da vivência dos seres humanos com seu ambiente. Okamoto (1997) ressalta que mesmo os atuais conceitos de valores correspondem a um paradigma do passado onde a forma, a aparência e os valores materiais têm a maior importância.

As pessoas sempre exercitaram o reconhecimento das condições ambientais que lhes são transmitidas pelos estímulos sensoriais, conferidos por seus sistemas de visão, tato, audição, paladar ou de olfato.

Mas não ficam restritas a uma percepção unicamente sensorial. Passam a processar em suas mentes aquilo que é percebido por suas sensações e progressivamente adquirem uma compreensão sobre o ambiente que as cerca. Assim se desenvolve o registro de suas percepções para o nível do conhecimento, para a inteligência. Castello (1998) chama a este processo de cognição ambiental.

Observa-se que é pela visão e percepção que se pode conhecer, com melhor exatidão, o nível de consciência ambiental individual e, considerando um âmbito global, a visão da consciência ambiental comunitária ou coletiva. 
É dentro dessa lógica que se pode desenvolver um aprendizado com o ambiente. Os usos e ocupação do espaço estão intimamente relacionados aos fenômenos ambientais que ali atuam e que explicam a configuração daquele ambiente.

A compreensão deste fato - a percepção ambiental - possibilita àqueles que estão sensibilizados para detectar estes relacionamentos assumirem comportamentos que lhes permitem beneficiar-se das condições prevalentes. Afirma Castello (1998) que é a partir das percepções que indivíduos e grupos têm sobre os recursos e o uso desses recursos que se moldam as próprias mudanças no uso dos recursos.

Esta atitude, geralmente de caráter pessoal, deve ser transmitida aos demais membros da comunidade, num processo chamado educação ambiental. Ao ser ambientalmente educado, espera-se que surjam novas atitudes ou comportamentos adequados para a elevação da qualidade de vida da comunidade.

É o que ressalta Castello (1998), quando diz que "a percepção tem dupla função didática: no tradicional binômio educando-educador, pode transformar os próprios educadores em educandos, ensinando-lhes como compreender o ambiente ao revelar-lhes os valores pelos quais aqueles que eles irão educar percebem o seu ambiente. Enquanto os educados, por seu turno, podem ser instruídos sobre alternativas e técnicas a adotar nas relações com seu ambiente".

Aqui se nota a necessidade da iniciativa de se criar novos meios e alternativas para despertar a sensibilização ambiental. Em uma comunidade sensibilizada, a educação ambiental será aplicada com maior eficiência, gerando novos comportamentos.

No meio acadêmico, algumas experiências de avaliação da percepção ambiental produziram efeitos colaterais de educação ambiental. (ANEXO A). O fato da confrontação das pessoas com as condições do meio onde vivem foi, em casos relatados na literatura, suficiente para a tomada de novas atitudes e iniciativas de grande valor socioambiental. Fernandes (2002) tratou um universo de 1.449 alunos e detectou que o desenvolvimento do estudo irá definir elementos concretos para o direcionamento de novos conhecimentos relacionados ao tema "meio ambiente", estruturará ações para áreas específicas a serem trabalhadas com aos alunos, identificará em outras áreas acadêmicas a possibilidade da temática ambiental ser formalmente inserida, bem como propiciará a oferta de cursos de extensão específicos, passíveis de serem oferecidos aos alunos e à sociedade como um todo.

De acordo com definição de Berlson e Steiner, citado por Kotler (2000), a percepção é “o processo por meio do qual uma pessoa seleciona, organiza e interpreta as informações recebidas para criar uma imagem significativa do mundo". Kotler (2000) menciona três processos relacionados à percepção: atenção seletiva, distorção seletiva e retenção seletiva.

O primeiro aspecto, a atenção seletiva, é o processo pelo qual o indivíduo filtra as informações. Neste aspecto, o desafio é saber que estímulos a pessoa perceberá. A distorção seletiva é o processo pelo qual o indivíduo intercepta as informações e as interpreta, de maneira a adaptá-la aos seus prejulgamentos. Finalmente, o processo de retenção seletiva é aquele em que as informações significativas, de acordo com as crenças e atitudes pessoais, são mantidas na memória do indivíduo.

No ambiente complexo do mercado moderno, a abordagem sistemática ao problema de marketing é cada vez mais importante. Com ênfase crescente na satisfação das necessidades individuais de determinadas espécies de consumidores, onde quer que se encontrem, é essencial que se empreenda alguma espécie de pesquisa organizada, a fim de identificar oportunidades de mercado e necessidades e desejos da sociedade (KOTLER, 2000).

Em termos conceituais, marketing define que uma empresa deve fazer o que pode vender, em vez de vender o que pode fazer. O marketing demanda o conhecimento das necessidades dos consumidores, obtido por meio de pesquisas de mercado, bem como da orientação das atividades empresariais para satisfazer tais necessidades. Em geral, os atuais clientes se dispõem a ajudar na definição de novos serviços e produtos. Note-se que a atividade primordial mercadológica é a pesquisa de mercado. O objetivo da coleta e análise das informações sobre o mercado e clientes de um estabelecimento visa a determinar quem está comprando seus produtos, por que, quando e em que circunstâncias.

A identificação das necessidades do cliente acarreta a investigação sistemática dos mercados, tanto dos que estão atualmente sendo fornecidos como os de novas áreas de mercado de interesse potencial. A pesquisa de marketing tem amplo alcance em suas indagações: cobre o desenvolvimento de 
produto, identificação de mercado, métodos adequados de venda, distribuição, promoção e serviços de apoio às vendas, ou seja, todos os aspectos da atividade empresarial a partir do "estágio de idéia" até a satisfação final do consumidor.

A pesquisa de marketing implica uma abordagem disciplinada aos problemas mercadológicos de várias espécies. Com o desenvolvimento de organizações e comportamento sofisticado das empresas, estes problemas tendem a tornar-se mais complexos e as decisões para resolvê-los têm efeitos de grande alcance. A pesquisa de marketing possui uma série de passos que devem ser dados para que gradativamente se desenvolva, planeje e execute a pesquisa nos âmbitos específicos. São eles: (KOTLER, 1993).

- definir o problema de marketing a ser investigado;

- construir um projeto simples para servir como guia para a realização da pesquisa em certas linhas;

- coletar os dados como especificado no projeto para o problema;

- analisar e avaliar os dados obtidos durante a pesquisa;

- preparar o relatório final do levantamento da pesquisa.

A informação é a vida dos levantamentos de pesquisa. Podem ser identificadas duas classificações de dados:

a) dados Primários: dados que foram coligidos pela primeira vez por qualquer combinação de: observação, experimentação ou questionários;

b) dados Secundários: informação existente que talvez seja útil para as finalidades de levantamentos específicos. Pode ser conseguida interna ou externamente.

A maioria das investigações de marketing utiliza alguma forma de questionário. Isso pode ser feito pelo correio ou em entrevistas pessoais. A entrevista pessoal é o método mais comum, quando os dados primários podem ser coletados diretamente dos questionados dos mercados industriais e de consumo. Ela é flexível e capaz de proporcionar uma vasta série de novos dados de grande importância.

O tipo de questionário depende do método de levantamento e este depende da natureza do problema que está sendo investigado, da espécie de população amostrada e do tamanho da amostra. Independentemente de como o questionário foi formado, as perguntas devem ser formuladas de modo que os questionados dêem a informação válida e confiável sobre o assunto sob pesquisa e o façam com um mínimo de distorção ou viés (KOTLER, 1993).

O questionário é uma parte vital da maioria dos levantamentos e há necessidade de grande perícia para formular uma boa série de perguntas. Deve-se cuidar para ficar dentro do vocabulário usado pela população que está sendo amostrada, evitando palavras que não comuniquem o significado das questões de modo claro e preciso.

A pergunta inicial deve ser tão interessante quanto possível para o entrevistado e bastante fácil de responder. As perguntas seguintes devem orientar o pensamento do respondente em uma progressão lógica de um tópico para o próximo.

Kotler (1993) recomenda o uso de perguntas-filtro para estabelecer se os questionados são ou não usuários dos produtos que fazem parte da pesquisa. Se as respostas forem afirmativas, podem abranger aspectos particulares do problema. Por exemplo: "Você fuma?" Sim/Não. Os que respondem "Sim" podem ser questionados se fumam charutos, cachimbo ou cigarros e, talvez, quantas vezes por dia ou por semana. Para os que não fumam, estas perguntas devem ser omitidas, passando às outras da seqüência.

As perguntas de classificação, como as de idade, sexo, estado civil, renda, educação, etc., normalmente devem ser deixadas para a parte final da entrevista.

A redação das perguntas tanto é arte como ciência; não existe uma solução geral que se possa aplicar livremente, embora haja alguns princípios de orientação que auxiliam nesta tarefa difícil. As perguntas são a matéria-prima dos questionários e delas depende a qualidade da pesquisa. As perguntas 
devem ser curtas, sendo que as complexas devem ser subdivididas em uma série de perguntas curtas e de resposta fácil que focalizem a atenção sobre uma questão específica e bem definida.

O viés deve ser evitado em todas as perguntas: isto quer dizer que elas devem ser cuidadosamente formuladas, evitando sugerir que certas respostas são mais aceitáveis que outras. As perguntas não devem exigir um excesso de tensão e esforço de memória dos questionados.

\section{MATERIAIS E MÉTODOS}

O questionário foi elaborado por um grupo de associados do IDS, com formações em engenharia florestal e sociologia. Buscou elaborar perguntas fáceis à compreensão dos agricultores, levando-os a informar sobre a existência de pinheiros em sua propriedade, sobre seu conhecimento das normas para o aproveitamento daquelas árvores, sobre as práticas de corte das mudas, concluindo com informações qualitativas, sobre ser ou não vantajoso plantar a espécie.

A definição do público-alvo da pesquisa foi feita à luz dos objetivos, a saber, levantar como a população rural, proprietários e prepostos percebe o valor dos pinheirais que possuem (ou deixaram de ter) em seus imóveis rurais. Assim, o público-alvo foi a comunidade rural. Os meios utilizados para alcançá-la poderiam ser visitas às propriedades, ou sua convocação pública a um local e data definidos, ou comparecendo em lugares onde esta se concentra.

A primeira alternativa não foi utilizada em função dos custos e tempo que seriam necessários dispor, inexistentes na Organização promotora da pesquisa; a segunda alternativa poderia ser mascarada ao se atrair apenas uma parcela da população, com pensamentos definidos acerca da questão, logo, com riscos de não se levantar o problema de maneira imparcial. Logo a terceira alternativa foi escolhida, foram determinados os locais mais freqüentemente recorridos pelos agricultores, notadamente os com poder de decisão: proprietários e prepostos. Das alternativas estudadas (bancos, sindicatos rurais, prefeituras e lojas de produtos agropecuários), foram escolhidas as lojas de produtos agropecuários em função da heterogeneidade dos pesquisados e pelo auxílio prestado pelos lojistas.

Foi realizado um levantamento piloto a 15 agricultores detentores de pinheirais, em propriedades localizadas no município de Colombo, Paraná, para verificar a sua eficiência. Tais questionários foram aplicados por um aluno de Engenharia Ambiental da PUCPR, que, posteriormente, recomendou algumas alterações dos termos utilizados, de forma a tornar mais claras as questões.

Foram distribuídos 2000 questionários (ANEXO B) em casas agropecuárias, cem por loja, em 12 cidades paranaenses. No envelope que cada lojista recebeu, havia uma carta de apresentação e recomendações de procedimentos para a pesquisa, 100 folhas de questionários e um cartaz "aviso" para ser afixado em local visível, solicitando aos clientes responder o questionário. Além desses, foi entregue uma camiseta da campanha a ser usada por um adolescente (filho do lojista ou de empregado deste) durante as entrevistas (ANEXO C).

Os objetivos foram apresentados aos lojistas. As explicações por escrito foram complementadas pelas verbais, recomendando os procedimentos das entrevistas. Em termos gerais, as informações foram as seguintes:

1. os comerciantes de agropecuária foram solicitados a permitir que se usasse seu estabelecimento para fazer as entrevistas entre seus clientes. Foram informados que se tratava de um questionário sobre os problemas com o Pinheiro-do-Paraná, inclusive os relacionados com a legislação. $\mathrm{Na}$ oportunidade, foi oferecido, além de uma camiseta da campanha, o pagamento de $\mathrm{R} \$ 0,20$ por folha preenchida. Além disso, o comerciante cooperador ganharia um diploma de Amigo da Araucária;

2. foi também sugerido que os questionários poderiam ser preenchidos pelos agricultores clientes da loja. Isso seria feito servindo-se de formulários que deveriam ficar à disposição em um balcão, atraídos pelo aviso. Outra alternativa seria o Comerciante designar alguém 
- que ganharia a camiseta da Campanha - para ajudar os agricultores que tivessem dificuldade para preencher o questionário:

3. na ocasião da entrega das fichas, foi informada a data do recolhimento dos formulários, em torno de 15 dias depois, ainda que fosse possível em um só dia preencher todos os 100 formulários. No momento do recolhimento foram coletados os dados do comerciante, para emissão do Certificado de Amigo da Araucária. Os comerciantes também receberam o telefone da ONG para tirar eventuais dúvidas. Não se recebeu nenhum pedido de esclarecimentos.

A campanha foi realizada nos meses de setembro a outubro de 2003, em estabelecimentos comerciais agropecuários dos municípios de São João do Triunfo, São Mateus, Almirante Tamandaré, Palmas, União de Vitória, Irati, Imbituva, Almirante Tamandaré, Rio Branco, Lapa, São Mateus e Bocaiúva mediante a interpretação percentual ou relativa dos dados obtidos, de acordo com os formulários respondidos.

\section{RESULTADOS E DISCUSSÃO}

A apresentação dos resultados foi feita considerando a aplicação dos questionários, a saber, seu formato e método de distribuição, e os dados obtidos com os formulários respondidos.

\section{Resultados da aplicação dos questionários}

Os questionários foram distribuídos a 20 estabelecimentos comerciais situados em 12 municípios paranaenses, situados na região metropolitana de Curitiba e ao longo do eixo da rodovia que liga Curitiba a Palmas. Tentou-se distribuir envelopes em outros municípios, como Itaperuçu e Porto Amazonas, porém nenhum lojista aceitou participar, devido à proximidade do período eleitoral. Nos demais municípios, onde se encontrou maior disposição, muitos lojistas não viabilizaram a participação de seus clientes na pesquisa, informando que raros ou nenhum deles a quiseram responder.

Os estabelecimentos que não aceitaram participar argumentaram dificuldades particulares (espaço físico, pessoal) para sua aplicação; outros mostraram má-vontade e até temor em função da reação de empresas ou pessoas da região, devido à pesquisa estar sendo conduzida por uma ONG. Lamentavelmente, não foram registrados resultados e seus principais argumentos, inclusive aspectos concernentes à desinformação.

Não obstante, a falta de esforços dos lojistas pelas respostas, o coordenador da campanha informou que nenhum devolveu as camisetas que recebeu para o trabalho que deveria ser feito. Dos 2000 questionários enviados, retornaram 227 preenchidos, totalizando 11,35\%.

\section{Resultados da pesquisa}

As informações obtidas da tabulação dos questionários foram as seguintes: 1) Cerca de $47 \%$ dos entrevistados eram proprietários rurais; 2) 40\% eram empregados rurais; 3) 6\% eram arrendatários; e 4) cerca de 7\% não tinham ligação direta com propriedades rurais (office-boy, vendedores, autônomos, entre outros).

Nem todos os entrevistados informaram a área dos imóveis. As entrevistas identificaram 117 propriedades rurais, com uma área média de 105,3 hectares. Dos entrevistados, 61,23\% residiam no imóvel.

Nestas propriedades, as culturas predominantes - que garantiam sua renda - eram $45,4 \%$ pecuária, $40,5 \%$ agricultura e $9,7 \%$ reflorestamento. Foram identificadas propriedades com outros usos, por exemplo, destinadas à criação de peixes, floricultura, suinocultura, ranário, avícola, hortigranjeiros e para lazer.

A maioria das propriedades tem pinheiros, da ordem de $74,2 \%$, que pode ser maior, considerando que $5,7 \%$ não informaram sobre este quesito. Dos que informaram tê-los, a quantidade média foi de 110 árvores. Muitos entrevistados mostraram desinformação sobre que tipo de pinheiros se 
referia a entrevista, confundindo com pínus. Esta confusão desacreditou este quesito. Contudo, serviu para mostrar a necessidade de se instruir a comunidade rural sobre a diferença entre as espécies.

A confusão entre espécies foi notada em outros quesitos, como aquele que perguntou, dos pinheiros existentes, quantas propriedades os possuem exclusivamente plantados ou nativos, cujas respostas foram, respectivamente, $14,3 \%$ e $39,2 \%$. Os que possuem tanto plantados quanto nativos representam 12,9\%, restando sem informar 36\%. Destaque-se, contudo, que apenas 4,15\% informaram ter plantado, no ano de 2003, em média 45 árvores por propriedade.

Persistiu incerteza nas respostas também em outros quesitos, como o que pesquisou o número de árvores plantadas nos últimos três e dez anos, cujas respostas foram, respectivamente, 13,4\% (1.110 árvores) e 63,7\% (5.284 árvores).

Entretanto, à pergunta sobre a idade ou tamanho do pinheiro mais velho, dos que responderam, não parece haver dúvidas se tratar da araucária. Cinqüenta por cento afirmaram que as árvores têm entre 30 e 100 anos, ou com diâmetros máximos de $45 \mathrm{~cm}$.

Respondendo sobre o pinheiro mais novo do imóvel, a idade mínima encontrada foi de 3 meses e a média de 7 anos, com altura média de $77,4 \mathrm{~cm}$.

Dos que disseram possuir pinheirais (162 propriedades), muitos informaram que suas árvores produzem pinhão, da ordem de $82,7 \%$, cuja quantidade média não foi possível estimar por omissão de dados. As respostas sobre a destinação destes não parecem igualmente confiáveis: apenas 14,2\% informaram o ter fornecido para comercialização, em quantidades muito pequenas, para mercados, feiras, outros estabelecimentos e venda direta ao consumidor.

Às 52 propriedades sem pinheiros se perguntou por que não os possuíam. As respostas foram que $42,3 \%$ destas não se localizam em região de pinheiros, $11,5 \%$ argumentaram que os pinheirais "atrapalham" ou concorrem com outras culturas, 9,6\% disseram que ao comprar a propriedade já não havia pinheiros, $7,7 \%$ informaram que o terreno era impróprio, $7,7 \%$ os cortaram, $3,9 \%$ disseram que não receberam incentivos para plantar e/ou mantê-los, enquanto outros $17,3 \%$ deram outros motivos ou se eximiram de responder.

Dos $91,6 \%$ entrevistados, $26,4 \%$ responderam que conheciam outras propriedades onde foram plantados pinheiros e $73,6 \%$ não, sendo que os demais não responderam a essa questão.

De acordo com a entrevista, foram plantadas 64.928 mudas, em 114 propriedades, entretanto esse resultado não pode ser considerado confiável, pois muitos não sabiam a diferença entre Araucária e Pínus.

Apenas 14,5\% dos entrevistados afirmaram ter cortado pinheiros, 16,3 árvores em média por propriedade, referentes a um período médio de oito anos atrás.

A respeito da questão sobre as licenças de corte de pinheiros nativos, o resultado revelou que: 1) $76,65 \%$ responderam a esta questão; 2) 78,74\% destacaram que o aproveitamento só poderia ser feito com licença ambiental; 3) 27,01\% indicaram que tal licença não seria concedida; 4) 9,77\% afirmaram que o corte poderia ser feito; e 5) 5,75\% opinaram que dependeria das condições, exemplificando, principalmente, a necessidade de apresentação de projeto (plano de corte).

A respeito da questão sobre as licenças de corte de pinheiros plantados, o resultado revelou que: 1) $63,44 \%$ responderam; 2) $57,64 \%$ disseram que não é possível obter licença para isto; 3 ) $55,56 \%$ realçaram que isso só pode ser feito com licença ambiental; 4) 16,67\% afirmaram que o corte pode ser feito; e 5) 2,78\% afirmaram que isso dependeria, por exemplo, de projeto (plano de corte) do local da plantação.

A confusão apresentada nestes quesitos evidencia duas situações: a primeira, que há dúvidas generalizadas sobre as possibilidades ou não de se aproveitar as araucárias dos imóveis, sejam elas plantadas ou nativas. A população rural não está esclarecida sobre as possibilidades e restrições legais do aproveitamento madeireiro desta espécie. A segunda está na relativa inadequação da formulação do quesito.

A pergunta crítica do questionário buscou saber sobre o corte ou eliminação da regeneração natural de Araucária. O resultado revelou que 32,6\% dos entrevistados conheciam "alguém que cortou ou arrancou pinheirinhos recentemente", enquanto 35,24\% informaram desconhecer essa atitude. No entanto, 32,16\% se esquivaram de responder. Esses números, entretanto, destoam do que se comenta em outros ciclos da comunidade. 
Concluindo a entrevista, perguntou-se aos agricultores se consideravam o pinheiro um bom negócio. A maioria das respostas, $64,31 \%$, foi positiva, contudo $25,55 \%$ foram negativas. Um pequeno número, 9,25\%, não respondeu à questão e 3\% disse que dependia de alguns fatores externos.

Ao se questionar a razão de sua resposta anterior, fosse ela positiva ou negativa, $82,82 \%$ deram respostas na forma discursiva. Estas foram classificadas em ordem decrescente:

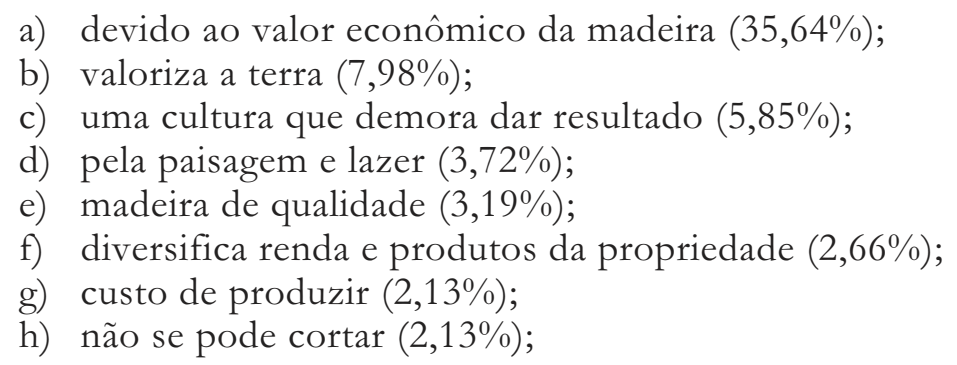

Outros comentários (36,7\%) foram difusos, por exemplo: que não há mais mercado para esta espécie, tem mercado para madeira e pinhão, produtos não madeiráveis, problemas com as leis pertinentes, etc.

A última pergunta continha uma prévia informação afirmativa: "Os pinheiros estão desaparecendo. O que se pode fazer para que voltem a ser valiosos?” As respostas foram dadas por $92 \%$ dos entrevistados, sendo as mais freqüentes, pela ordem de ocorrência:

a) florestando e reflorestando áreas, 55,02\%;

b) criar incentivos de alguma forma, 9,1\%;

c) conscientização do problema, 4,31\%;

d) aumentar o valor do produto (madeira, pinhão, etc.), 5,74\%.

Analisando estas estatísticas, vale a pena discutir algumas das informações anteriormente expostas:

A repetição de muitas respostas similares leva a crer que alguns entrevistadores podem ter "ajudado" os entrevistados, ou as entrevistas ocorreram em "roda de chimarrão", cujas conversas no momento da entrevista levaram os entrevistados a aproveitar as idéias que alguns apresentaram como resposta.

Muitas das questões que envolviam quantidades foram respondidas de forma evasiva, temendo a possibilidade de uma ação fiscalizatória. Isso aconteceu, por exemplo, nos quesitos sobre o conhecimento de quem teria cortado regeneração natural de Araucária, ou no que se produziu de pinhões, ou ainda, de casos de aproveitamentos de pinheiros nas propriedades. Uma conclusão apressada até permitiria avaliar que, em todos os municípios pesquisados, os povoamentos de araucária estariam íntegros, preservados e cheios de exemplares jovens, o que se sabe não ocorrer.

Acerca da aplicação dos questionários

O índice de retorno, de 11,5\% seria bastante significativo, considerando o que a literatura cita como retorno aceitável, em campanhas de opinião, que normalmente apresentam índices bem abaixo do obtido. Entretanto, esta conclusão poderia estar prejudicada se a análise estatística for estratificada - a parcialidade dos dados seria evidente se o conjunto das respostas proviesse unicamente de dois estabelecimentos comerciais que preenchessem todas as 100 fichas e, pior, se ambos fossem da mesma cidade. Note-se que a não distribuição em pelo menos duas cidades, porque os lojistas não aceitaram apoiar a pesquisa, poderia parcializar as respostas obtidas.

$\mathrm{Na}$ busca da não identificação do entrevistado, os questionários não indicaram a cidade e loja onde foram obtidos e a coleta dos dados não se preocupou nesta segregação dos dados. Não há, assim, como conferir a possibilidade da ocorrência da estratificação ou não dos dados.

Sabendo-se, da ONG, que tais dados vieram de pelo menos 11 procedências, as análises consideram sua distribuição como não estratificada. Nestas condições, tem-se que o índice de respostas é representativo da opinião coletiva sobre os pinheirais. 


\section{CONCLUSÕES}

Os coordenadores do Plano consideraram, à luz das suas expectativas e em primeira análise, insatisfatórios os resultados obtidos. Foram atribuídas a essa frustração as possíveis falhas na formulação dos quesitos e coleta dos dados, já que se esperava, tanto um número maior de retornos, como menor resistência dos entrevistados em dar as respostas. Entretanto, os dados ora apresentados permitem atenuar aquela expectativa crítica.

As perguntas do questionário foram, na maioria dos casos, preenchidas. Não obstante, notouse que em algumas, descritivas, alguns questionários pareciam ter tido auxílio de pessoas da loja, que induziram algumas respostas, o que se deduziu por essas serem repetitivas em vários formulários. Essa situação prejudicou algumas conclusões importantes, por exemplo, sobre o pensar de alguns agricultores sobre os valores do Pinheiro.

A respeito dos questionários, concluiu-se que esses poderiam ser mais breves, evitando quesitos assemelhados e com perguntas de caráter indicador. A metodologia de coleta de dados, à luz de outras pesquisas realizadas, certamente alcançou o objetivo pretendido, especialmente onde os lojistas se dispuseram a colaborar.

A análise dos resultados das entrevistas determinou o perfil das propriedades rurais e de seus ocupantes, do que se conclui que é baixa a percepção de valor, da comunidade rural paranaense, acerca do Pinheiro-do-Paraná. O perfil das propriedades abrangidas pelas entrevistas indica que as propriedades têm em média acima de 100 hectares, com usos predominantemente agropecuários, porém, em $75 \%$ delas existem pinheirais, com média 110 árvores por propriedade.

Praticamente não existem plantios de novos pinheirais. Os dados auscultados mostraram a ocorrência de plantios em menos de 15\% dos imóveis, sendo que, desses, pouco mais de 13\% ocorreu nos últimos três anos e 63,7\% (num total de apenas 5.284 árvores) teriam sido plantados nos últimos dez anos. Os pinheirais existentes estão, em sua maioria, produzindo pinhões. No entanto, detectouse em alguns questionários respostas desconcertantes, como naquelas em que os entrevistados mostraram-se com dúvidas, não diferenciando pelo termo "pinheiro", o gênero Araucaria, do Pinus ou de outra conífera similar. Outra questão surpreendente foi sobre o aproveitamento das araucárias, sejam elas plantadas ou nativas. A população rural não está esclarecida sobre as questões legais do aproveitamento madeireiro da araucária, o que a induz a preferir outras espécies, prejudicando a regeneração natural do pinheiro-do-Paraná (ANEXO A).

\section{REFERÊNCIAS}

CASTEllo, L. A percepção do ambiente: educando educadores. Porto Alegre: Urbanismo \& Ambiente, 1998.

FERNANDES, R. S. et al. Percepção ambiental dos alunos da faculdade brasileira - Univix, Vitória. 2002. Disponível em: <http://geocities.yahoo.com.br/geographica 2002/percepcaoalunos.htm>. Acesso em: 03 set. 2003.

IBAMA. Lista das espécies ameaçadas. Portaria no 37-N, de 3 de abril de 1992. Brasília: [s. n.], 1992.

IDS. Instituto do Desenvolvimento Sustentável. Plano GRIMPA. Apresentação. Disponível em: <www.grimpa.org.br>. Acesso em: 12 fev. 2004.

KOTLER, P. Administração de marketing. 10. ed. São Paulo: Prentice Hall, 2000. 
KOTLER, P. Administração de marketing: análise, planejamento, implementação e controle. São Paulo: Atlas, 1993.

OKAMOTO, J. Percepção ambiental: visão holística da percepção ambiental na arquitetura e comunicação. 2. ed. São Paulo: Ipsis, 1997.

SOS ARAUCÁRIA. Projeto SOS araucária. Disponível em: <http://www.sos.araucaria.com.br>. Acesso em: 11 jan. 2004.

UNIVERSIDADE FEDERAL DO PARANÁ - UFPR. Os números atuais da cobertura florestal do Paraná. Ambiente Brasil. 2003. Disponível em: <http://www.ambientebrasil.com.br.>. Acesso em: 20 mar. 2004.

Recebido em: 25/06/2006

Received in: 06/25/2006

Aprovado em: 30/09/2006

Accepted in: 09/30/2006 


\section{ANEXOS}

ANEXO A - Foto de resultado de atitude comum contra o Pinheiro-do-Paraná

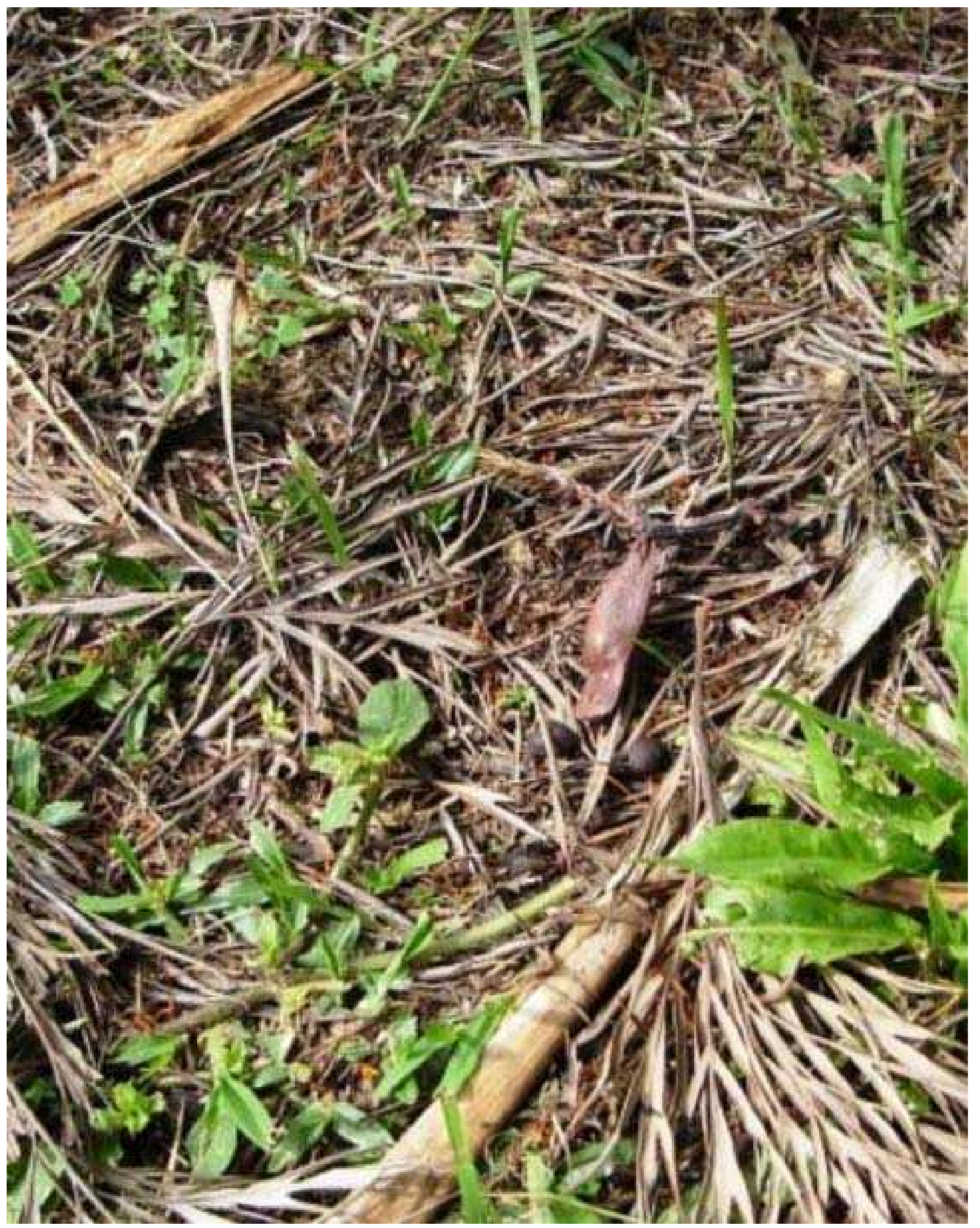

Rev. Acad., Curitiba, v. 5, n. 2, p. 117-130, abr./jun. 2007 
ANEXO B - Formulário aplicado na Pesquisa de Opinião Pública sobre o Pinheiro-do-Paraná

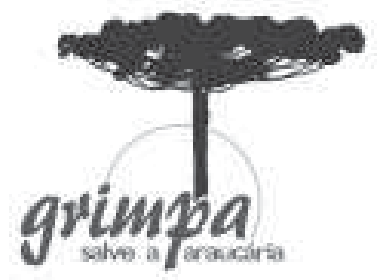

\section{PESQUISA DE OPINIÃO PÚBLICA SOBRE O PINHEIRO-DO-PARANÁ}

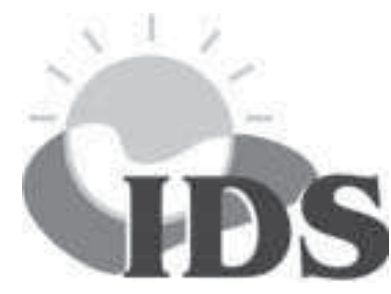

Você está participando de uma pesquisa sobre o Pinheiro-do-Paraná. Por favor, seja sincero: marque com um $X$, cite os números e diga o que você sabe sobre os dados solicitados.

Não assine esta folha.

Você é: proprietário rural ( ); empregado rural ( ); outro:

Que área tem a propriedade rural? Você mora lá? Sim ( ); Não ( )

De que tipo de cultura vem a renda principal do imóvel?

reflorestamento ( ); agricultura ( ); pecuária ( ); outros:

Nesta propriedade têm pinheiros? Sim ( ); Não ( ). Quantos, mais ou menos?

São pinheiros: plantados ( ); nativos ( ). Quantos foram plantados este ano?

Quantos foram plantados nos últimos três anos? e nos últimos dez anos

O pinheiro mais velho tem anos ou cm de circunferência;

O pinheirinho mais novo tem anos ou $\mathrm{cm}$ de altura $\mathrm{m}$

Seus pinheiros já produzem pinhão? Sim ( ); Não ( ). Que quantidade?

Foram vendidos? Sim ( ); Não ( ); Uma parte ( ) Quem comprou?

Se a propriedade não tiver pinheiros, por que não tem?

Você conhece propriedades que plantaram pinheiros neste ano? Sim ( ); Não ( )

Quantos pinheiros plantaram? Quantas propriedades?

Você já derrubou pinheiros no seu imóvel?

Quantos?

Há quanto tempo?

Se você precisar derrubar pinheiros nativos de seu imóvel: Pode? ( ); Só com licença? ( ); Não dão licença? ( ) Depende:

Se você for derrubar pinheiros plantados de seu imóvel: Pode? ( ); Só com licença? ( ); Não dão licença? ( ) Depende:

Sabe de alguém que arrancou pinheirinhos recentemente? $\operatorname{Sim}(\quad$ ); Não ( ).

O pinheiro é bom negócio? Sim ( ); Não ( ); Depende

Por quê?

Os pinheiros estão desaparecendo. O que se pode fazer para que voltem a ser valiosos?

Data:

Se quiser mandar um recado para o Grimpa, peça a folha de sugestões. 
ANEXO C - Fotos da camiseta e cartaz empregados como apoio para a pesquisa de campo
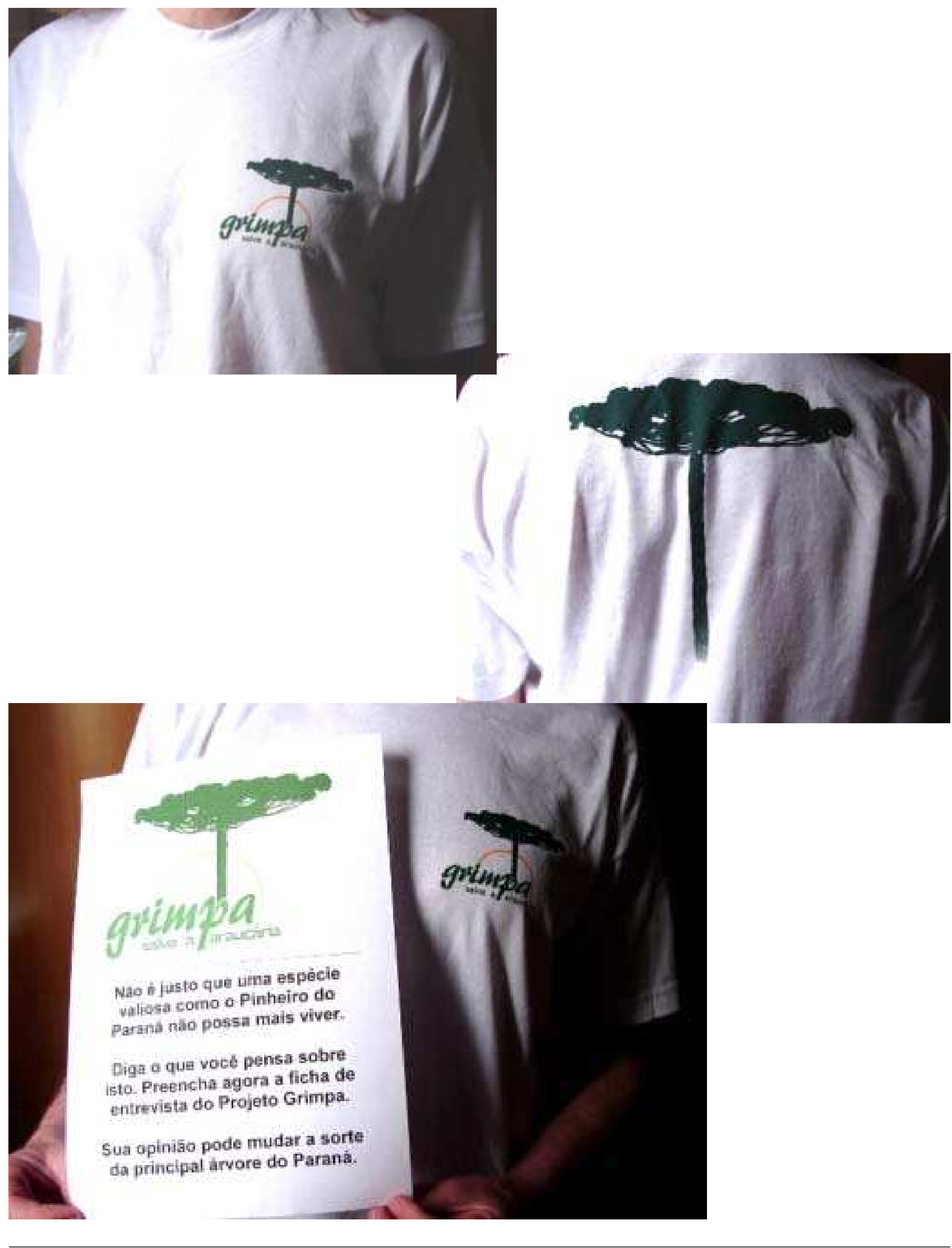

Rev. Acad., Curitiba, v. 5, n. 2, p. 117-130, abr./jun. 2007 